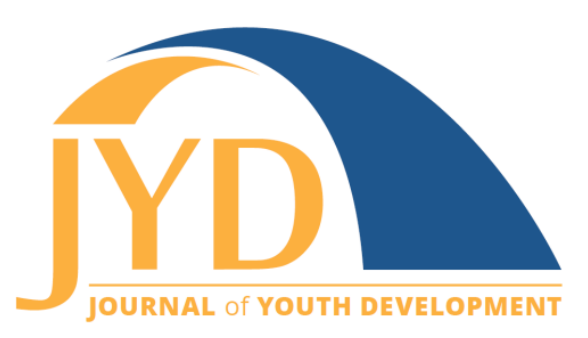

http://jyd.pitt.edu/ | Vol. 14 Issue 4 DOI 10.5195/jyd.2019.792 | ISSN 2325-4017 (online)

\title{
A Residential Camp's Impact on Youths' Leadership Skills and Natural Resource Knowledge
}

\author{
Shandra Nicole Frey \\ Utah State University Extension \\ nicki.frey@usu.edu \\ Vernon Parent \\ Utah State University Extension \\ vernon.parent@usu.edu
}

\begin{abstract}
Learning transcends the classroom. To better understand the natural world around them, it is critical that youth have opportunities to make connections and apply their learning in real-world settings. Improving youths' perceived skills and knowledge contributes to increased academic motivation and continued leadership development. Multi-day residential natural resource camps have shown the ability to teach ecological concepts and develop land management skills, critical thinking skills, and decision-making skills. We tested the ability of a remotely located residential camp to improve leadership skills and natural resource knowledge, using a pre-and post-camp self-assessment, combined with a pre-and post-camp knowledge test. The teaching strategies of the camp-independent investigations, discussion groups, interactions with field scientists, recreational activities, and group problem solving-resulted in participants feeling they had increased their leadership skills and knowledge of natural resource topics. The campers' perceived increase in knowledge was supported by an increase in score on a knowledgebased test. $A$ residential natural resource camp is an effective activity to engage youth to develop leadership skills and academic motivation, while connecting them to their natural environment.
\end{abstract}

Key words: youth leadership, natural resources, outdoor education, residential camp, self-assessment

With the growing urbanization of America, we have seen a dramatic reduction in opportunities for children to experience natural environments. Increasingly, K-12 educators struggle to engage students in agricultural and environmental education due to increasing demands from education standards and financial challenges. This reduced exposure to natural resources and environmental science education may correlate with decreased college enrollment in

(cc) EY New articles in this journal are licensed under a Creative Commons Attribution 4.0 License. This journal is published by the University Library System, University of Pittsburgh and is cosponsored by the University of Pittsburgh Press. The Journal of Youth Development is the official peer-reviewed publication of the National Association of Extension 4-H Agents and the National AfterSchool Association. 
Natural Resource Knowledge and Leadership Skills

natural resource and science disciplines. The National Science Board (2014) noted that the number of college students enrolled in the sciences has been steadily declining since 2010. Conversely, the demand for more scientists and experts in natural resources, particularly renewable energy, continues to grow (Bureau of Labor Statistics, 2017). To reestablish this workforce pipeline, youth need to be reengaged in science and natural resource subjects, and develop the skills necessary for successful postsecondary education and workplace integration. The National Research Council (2012) considers the following skills important indicators of academic and workplace readiness:

- cognitive process and strategies (e.g. critical thinking, problem solving),

- general knowledge (e.g. oral and written communication),

- positive core self-evaluation (e.g. self-confidence),

- teamwork and collaboration (e.g. interpersonal skills, teamwork), and

- leadership.

Residential camps located in natural settings (where youth spend several uninterrupted days and nights) may be the bridge that reengages the next generation of scientists and land managers with our natural resources. Previous research demonstrated that natural resource and biology camps create direct experiences designed to enhance environmental awareness and create a citizenry that cares about its natural surroundings (Andrejewski, 2011; Bogner, 1998; Dettmann-Easler \& Pease, 1999; Dresner \& Gill, 1994; Gibson \& Chase, 2002). These experiences then lead to increased interest in natural resources topics (San Jose \& Nelson, 2017).

Youths' motivation to learn and retain knowledge increases with the hands-on learning strategy of many natural resource educations camps (Knapp \& Poff, 2001; Nichols \& Utesch, 1998; Ryan \& Campa, 2000; San Jose \& Nelson, 2017; Yair, 2000). Past studies have focused on residential camps' ability to influence academic readiness, however, comparatively few have focused on their ability to improve skills such as leadership, self-confidence, communication, and the ability to collaborate (hereafter referred to collectively as leadership skills). Residential camps provide additional learning opportunities for youth to build these leadership skills by providing an extended learning environment with new opportunities to practice leadership, build academic and workplace readiness, and achieve goals (Griffin, Glasscock, Schwertner, Atchley, \& Tarpley, 2016; Wilson \& Sibthorp, 2018). Other studies have suggested that science camps improve the self-confidence and independence of participants through new social encounters, new activities, and leadership opportunities created within a neutral environment (Bhattacharyya, Nathaniel, \& 
Mead, 2011; Dettmann-Easler \& Pease, 1999; Dresner \& Gill, 1994; Riedinger, 2015; Thurber, Scanlin, Scheuler, \& Henderson, 2007; Wilson \& Sibthorp, 2018).

Hindes (2011) suggests that the belief that one has the personal capabilities and resources to meet the demands of a specific task ("self-concept") can influence skills and impact performance as a leader. Competency in a subject (including knowledge) and self-concept as a leader are instrumental in developing the intrinsic motivation of youths toward academic endeavors and leadership development (Faye and Sharpe, 2008; Hindes, 2011; Love, 2003). To meet the needs of the next generation of scientists, a natural resource camp must help to increase academic interest in natural resources as well as increase leadership, self-confidence, and interpersonal communication.

\section{Background of the Color Country Natural Resource Camp}

The Color Country Natural Resource Camp (CCNRC) was developed in 1991, through collaboration between high-school teachers and natural resource professionals in Washington County, southern Utah. Camp leaders organized the experience to accomplish three objectives: increase participant leadership and communication skills, increase exposure and abilities in outdoor recreation, and increase knowledge of natural resources and jobs. The camp recruits high school students aged 16-18, advertising mainly through biology and agricultural science teachers.

CCNRC is a 5-day co-ed residential camp located in a remote, high elevation, dispersed camping site. Counselors are a mix of supporting natural resource agency personnel, secondary education and university Extension professionals, and other adult volunteers. The curriculum uses an active learning strategy (intentional activities that encourage campers to apply what they are learning, including problem-solving, cooperative projects, simulations, and role playing), which can increase communication and leadership skills while teaching participants natural resources principles (Ryan \& Campa, 2000).

Investigating real issues through experimentation facilitates students' academic achievement (Yair, 2000). Each day campers rotate through four natural resource investigations-aquatics, wildlife, soils and land use, and vegetation-led by professionals in these topics. Each investigation lasts 3 to 4 hours. Instructors provide campers with the baseline information needed to accomplish their tasks and guide them through hands-on activities that lead the campers to ask a question, collect data, and determine an answer through inquiry-based 
Natural Resource Knowledge and Leadership Skills

learning. To allow campers to attend the camp twice, each natural resource topic has two sets of curricula that address different concepts and skills alternating between odd and even years.

To provide opportunities for practical and applied use of the knowledge learned in the investigations, CCNRC blends environmental education with outdoor recreation (e.g., mountain biking. canoeing, etc.). Outdoor recreation exposes youth to wildlife and plants, aquatic environments, and different land management strategies (e.g., National Park Service, local state parks, U.S. Forest Service), providing opportunities for campers to reinforce what they have learned during their natural resource investigations. For example, a camper may observe plants while mountain biking, and recall the names of the plants that they learned during a botany class. With this in mind, the CCNRC campers spend the second half of each day participating in horseback riding, archery, riflery, canoeing, mountain biking, or orienteering. Over the course of their stay, campers participate in four of these activities where they may learn they have skills they were not aware of or realize they may have leadership qualities as they help less experienced campers during the recreational activity. These accomplishments can break down the boundaries of traditional cliques and identities that campers have when they show up to camp, opening avenues for increased learning, increased confidence, an adjustment of selfconcept, and increased motivation (Anderson-Howe, 1993; Dresner \& Gill, 1994; Hindes, 2011; Riedinger, 2015).

Knowledge and leadership increase when participants are given time to consider their experiences and contemplate how their lessons fit into the natural world (Bexell, Jarrett, \& Ping, 2013). CCNRC incorporates journaling into the camp itinerary to expand campers' writing experiences and allow time for contemplation. At least once a day, a camp instructor facilitates journaling exercises, such as reading an excerpt from literature and writing how this relates to the campers' lives or experiences. The campers may write about an event that happened during CCRNC and how that influenced them, or simply free-write what is on their minds. Additionally, campers keep field notes within their journal for each of their investigations. These exercises expose campers to both expository and scientific writing related to the natural world. At the end of the camp, instructors review these journals to gain qualitative insights into each investigations' effectiveness at engaging the campers.

CCNRC concludes with a team project that requires campers to draw upon everything they learned that week. Depending on the year, campers either participate in a debate competition centering on a natural resource issue or collaborate to create data collection methods, recommend improvements, and develop an interpretation for a hypothetical new natural 
Natural Resource Knowledge and Leadership Skills

resource center at the camp location. During these activities, campers practice their leadership and collaboration skills, and synthesize their knowledge to solve questions.

Although CCNRC has provided campers with natural resource education and experiences for 25 years, we have never assessed the effect of the program on campers' leadership skills or knowledge attainment. In this study, we were interested in determining if our remote residential camp improved camper's perception of their own leadership skills and how their perceived knowledge of natural resources compared to actual knowledge gained.

\section{Methods}

We designed this study to measure

- perceived change in leadership skills (e.g., cognitive process and strategies, general knowledge, positive core self-evaluation, teamwork and collaboration, leadership; National Research Council, 2012),

- perceived increased knowledge in natural resource topics,

- actual increase in knowledge, and

- increased participants' interest in natural resource careers.

Our goal was to use the results to guide improvements to camp curriculum and the camp experience.

To determine the impact of the camp, we conducted a standard pre-post survey from 2013 to 2016. This was done immediately before and after campers' participation in the camp. Each year 24 to 38 campers attended camp. During our pre-camp meeting with participants and their parents, we administered a pre-camp questionnaire. The questionnaire was comprised of three parts: a survey of campers' perceived attitudes and abilities in elements of leadership and communication (i.e. leadership skills), a survey of their perceived knowledge of natural resource topics and a 12-question test of basic ecological concepts that would subsequently be covered during camp investigation exercises. Campers were assigned a numerical code to use in place of their name to ensure confidentiality.

We administered a scaled-response survey on perceived knowledge and experience with investigations from 2013 to 2016, using a categorical selection with a 5-factor rating scale. For each investigation topic, campers selected from the following skill levels: 1 (none), 2 (heard about it), 3 (some), 4 (quite a bit), and 5 (leader). We added a scaled-response survey of perceived leadership skills in 2014, with a 6-factor rating scale, and included this section 
Natural Resource Knowledge and Leadership Skills

through 2016. We provide a list of 'leadership' statements and available responses in the Appendix.

The number of rating scale factors and possible responses differs from traditional Likert-scale surveys. Empirical evidence suggests that item specific scale labels, directly correlating to the question, increase data quality (DeCastellarnau, 2018). Therefore, for example, we paired our questions of "how familiar are you with wildlife management" with the possible responses "none, heard about it, some, quite a bit, I consider myself a leader." Similarly, there is no determination as to the most appropriate number of responses to provide in a scaled-response survey, although there must be enough response statements to provide a relatable option for the respondents (DeCastellarnau, 2018). For leadership statements (e.g., "I feel comfortable speaking in front of adults") campers selected from 0 (absolutely not), 1 (not usually), 2 (sometimes, it depends), 3 (about $50 \%$ of the time), 4 (usually), or 5 (yes, all of the time).

The last section of the questionnaire was an open-ended question format consisting of eight to 12 questions. The test consisted of one to three questions on each of the following subjects: wildlife, vegetation, aquatics, and archeology (vegetation and archeology had one question each in 2013, and three questions each in years 2014 to 2016).

We administered the post-camp survey during the last day of camp, utilizing the same procedure and camper identification used for the pretest. Campers were reminded that their responses would not be read by any instructors. While the questions were identical to the precamp survey, we changed the verbiage to reflect that we were asking participants to record their change in attitudes as a result of being at camp.

\section{Data Analysis}

\section{Change in Perception}

To be considered for the analysis, campers had to have completed both the pre- and post-camp questionnaires. After removing those campers that had not completed both surveys we used 69 surveys for perceived leadership, and 97 surveys for perceived knowledge. We calculated the average change in rating from pretest to posttest for each question in both the leadership and knowledge sections of the questionnaire. Next, we conducted a Wilcoxon paired signed-rank test to determine campers' change in attitude pre- and post-camp experience, similar to Bogner (1998). The Wilcoxon paired signed-rank test is the non-parametric version of the paired $t$-test; 


\section{Natural Resource Knowledge and Leadership Skills}

suitable for small, non-normally distributed datasets. The Wilcoxon test evaluates the difference in rank from pretest to posttest for each participant (i.e. a paired sample), and considers the median of the set of differences (Dahlgaard, 2008). This test allows for the detection of outliers and response shift among the respondents. Our hypothesis was that the median would be different from 0 . We considered a reported $p$ value of $<.05$ as statistically significant. The Wilcoxon paired signed-rank test statistic is represented by $V$, a value representing the relative difference between the two groups tested that is subject to interpretation; therefore, we also included the mean rank difference ( \pm standard error) to aid in the interpretation of our results.

\section{Change in Knowledge}

We designed the final part of our questionnaire as a quiz, to test campers' knowledge of the four natural resource subjects we investigate during camp. We grouped the questions by subject for analysis: wildlife, aquatics, vegetation, and archeology. We tested the increase in knowledge by comparing the number of questions answered correctly before the camp to those answered correctly after the camp. After removing those campers that hadn't completed the post-camp knowledge quiz, we used 92 surveys for this analysis. We conducted a McNemar test to evaluate the results; this is a non-parametric, within-subject chi-square test that measures pre and post dichotomous (correct/incorrect) responses. Statistical significance was recognized at $p<.05$.

\section{Results}

From 2014-2016, 69 campers completed the pre- and post-camp 'leadership' sections of the questionnaire (this section was not included in 2013). From 2013-2016, 97 campers completed the pre- and post-camp perceived knowledge section of the questionnaire, and 92 campers completed the pre- and post-camp knowledge quiz.

\section{Perception of Leadership Skills and Knowledge}

The CCNRC camp positively influenced campers' perceptions of many of the leadership skills identified in our survey (Table 1). The greatest perceived change occurred in the participants' ability to collect and record data (average rating increase of 0.6 ) and speaking in front of adults (average rating increase of 0.5 ). Additionally, campers' ranking of their ability to analyze data and draw conclusions, speak around people their own age, and work as a part of a group also increased after attending camp. However, the campers' perceptions of their ability to solve 
Natural Resource Knowledge and Leadership Skills

problems on their own or as a group did not improve. Nor did their perceptions as to their ability to use technological tools, their interest in learning new facts, or influence their interest in attending a 4-year college increase (Table 1). For each statement, a proportion of campers ranked their perceived leadership lower on the post-survey, resulting in a negative change (Table 1). The proportion of campers' rankings resulting in a negative change was relatively large for several statements, including "I would like to attend a 4-year college."

The results of the pre-post survey of campers indicated that the camp positively influenced campers' ratings of their perceived knowledge of natural resources topics (Table 2). Telemetry, astronomy, and avian ecology were not offered each year, resulting in a lower sample size of campers for these investigations. The greatest perceived increases in knowledge were reflected in aquatics, avian ecology, and telemetry. However, the campers did not perceive an increased knowledge in astronomy. Similar to the perceived leadership survey, a proportion of campers indicated a lower ranking on their post-camp survey, resulting in a negative change in perceived ability (Table 2). For some investigations, the proportion was relatively large; $64 \%$ of the campers' responses resulted in a negative change for astronomy and telemetry. 
Journal of Youth Development | http://jyd.pitt.edu/ | Vol. 14 Issue 4 DOI 10.5195/jyd.2019.792 Natural Resource Knowledge and Leadership Skills

Table 1. Comparison of Participants' Leadership Skills Survey Responses Before and After CCNRC attendance, 2014 - 2016.

\begin{tabular}{|c|c|c|c|c|}
\hline \multicolumn{5}{|l|}{ Question } \\
\hline $\begin{array}{l}\text { Average ranking } \\
\text { post-camp } \pm \\
\text { standard error }\end{array}$ & $\begin{array}{l}\text { Average rating change } \\
\text { from pre-camp to post- } \\
\text { camp } \pm \text { standard error }\end{array}$ & $\boldsymbol{V}$ & $p$-value & $\begin{array}{l}\% \text { responses } \\
\text { with a negative } \\
\text { change in rating }\end{array}$ \\
\hline \multicolumn{5}{|c|}{ I am good at recording and collecting data. } \\
\hline $4.2 \pm 0.1$ & $0.6 \pm 0.15$ & 245.5 & $<.005$ & 14.5 \\
\hline \multicolumn{5}{|c|}{ I feel comfortable speaking in front of adults. } \\
\hline $4.1 \pm 0.1$ & $0.5 \pm 0.13$ & 242 & $<.001$ & 15.9 \\
\hline \multicolumn{5}{|c|}{ I am good at analyzing data that was collected. } \\
\hline $4.0 \pm 0.1$ & $0.4 \pm 0.15$ & 363 & .002 & 17.4 \\
\hline \multicolumn{5}{|c|}{ I feel comfortable speaking around people my age. } \\
\hline $4.2 \pm 0.1$ & $0.3 \pm 0.12$ & 222.5 & .006 & 17.4 \\
\hline \multicolumn{5}{|c|}{ I am interested in a natural resources career. } \\
\hline $4.0 \pm 0.1$ & $0.3 \pm 0.13$ & 163 & .005 & 14.5 \\
\hline \multicolumn{5}{|c|}{ I enjoy trying new activities. } \\
\hline $4.7 \pm 0.07$ & $0.3 \pm 0.10$ & 88 & .005 & 11.6 \\
\hline \multicolumn{5}{|c|}{ I like to be the leader in group activities. } \\
\hline $3.4 \pm 0.2$ & $0.3 \pm 0.16$ & 277.5 & .03 & 18.8 \\
\hline \multicolumn{5}{|c|}{ I am good at drawing conclusions from scientific observations. } \\
\hline $4.0 \pm 0.1$ & $0.3 \pm 0.13$ & 220.5 & .004 & 14.5 \\
\hline \multicolumn{5}{|c|}{ I am comfortable solving problems as part of a group. } \\
\hline $4.3 \pm 0.1$ & $0.2 \pm 0.13$ & 241 & .06 & 17.4 \\
\hline \multicolumn{5}{|c|}{ I am confident solving problems on my own, not as a group. } \\
\hline $3.8 \pm 0.1$ & $0.04 \pm 0.16$ & 445 & .19 & 26.1 \\
\hline \multicolumn{5}{|c|}{ I enjoy learning new facts. } \\
\hline $4.5 \pm 0.1$ & $0.01 \pm 0.14$ & 121 & .19 & 13.0 \\
\hline \multicolumn{5}{|c|}{ I am comfortable using technological tools (computer software, GPS, etc.). } \\
\hline $3.9 \pm 0.1$ & $-0.04 \pm 0.17$ & 463.5 & .56 & 26.1 \\
\hline \multicolumn{5}{|c|}{ I would like to attend a 4-year college. } \\
\hline $4.1 \pm 0.1$ & $-0.1 \pm 0.13$ & 432.5 & .96 & 33.3 \\
\hline
\end{tabular}

Note. $V=$ Wilcoxson's ranked sum test statistic. Responses were based on a rating scale of 1 to 6,6 indicating the highest level of skill or comfort level. 
Journal of Youth Development | http://jyd.pitt.edu/ | Vol. 14 Issue 4 DOI 10.5195/jyd.2019.792

Natural Resource Knowledge and Leadership Skills

Table 2: Comparison of Participants' Natural Resources Knowledge Survey Responses Before and After CCNRC Attendance, 2013 - 2016.

\begin{tabular}{|c|c|c|c|c|}
\hline \multicolumn{5}{|l|}{ Subject $\left(n^{*}\right)$} \\
\hline $\begin{array}{l}\text { Average rating } \\
\text { post-camp } \pm \\
\text { standard error }\end{array}$ & $\begin{array}{l}\text { Average rating change } \\
\text { from pre-camp to post- } \\
\text { camp } \pm \text { standard error }\end{array}$ & $\boldsymbol{V}$ & $p$-value & $\begin{array}{l}\% \text { responses } \\
\text { with a negative } \\
\text { change in rating }\end{array}$ \\
\hline \multicolumn{5}{|l|}{ Telemetry (22) } \\
\hline $3.09 \pm 0.32$ & $1.41 \pm 0.29$ & 11 & $<.001$ & 63.6 \\
\hline \multicolumn{5}{|l|}{ Avian ecology (68) } \\
\hline $3.4 \pm 0.09$ & $1.29 \pm 0.11$ & 0 & $<.001$ & 0.0 \\
\hline \multicolumn{5}{|l|}{ Aquatics (90) } \\
\hline $3.8 \pm 0.07$ & $1.22 \pm 0.11$ & 42.5 & $<.001$ & 1.1 \\
\hline \multicolumn{5}{|l|}{ Archeology (90) } \\
\hline $3.8 \pm 0.07$ & $1.22 \pm 0.11$ & 42.5 & $<.001$ & 1.1 \\
\hline \multicolumn{5}{|c|}{ Outdoor recreation/land use (89) } \\
\hline $4.1 \pm 0.08$ & $1.17 \pm 0.13$ & 93 & $<.001$ & 3.3 \\
\hline \multicolumn{5}{|l|}{ Vegetation (89) } \\
\hline $3.9 \pm 0.06$ & $1.13 \pm 0.10$ & 20.5 & $<.001$ & 1.1 \\
\hline \multicolumn{5}{|l|}{ Wildlife (90) } \\
\hline $3.9 \pm 0.06$ & $0.95 \pm 0.1$ & 0 & $<.001$ & 1.1 \\
\hline \multicolumn{5}{|l|}{ GPS (90) } \\
\hline $3.9 \pm 0.09$ & $0.67 \pm 0.11$ & 180 & $<.001$ & 9.9 \\
\hline \multicolumn{5}{|c|}{ Outdoor survival (90) } \\
\hline $4.0 \pm 0.09$ & $0.38 \pm 0.11$ & 250.5 & $<.001$ & 13.2 \\
\hline \multicolumn{5}{|l|}{ Astronomy (32) } \\
\hline $1.9 \pm 0.32$ & $-0.38 \pm 0.27$ & 154 & .91 & 63.6 \\
\hline
\end{tabular}

Note. *Telemetry, astronomy, and avian ecology were not offered every year, hence the sample size $(n)$ for those investigations was smaller than for other topics. $V=$ Wilcoxson's ranked sum test statistic. Responses were based on a rating scale of 1 to 5 , with 5 representing the highest level of knowledge.

\section{Knowledge of Natural Resources}

The results of the McNemar chi-square test (Table 3) suggest that each investigation tested was successful at increasing the knowledge of campers. 
Natural Resource Knowledge and Leadership Skills

Table 3. Comparison of the Frequency of Correct Answers Before and After CCNRC, 2013-2016.

\begin{tabular}{|l|c|c|c|c|c|c|}
\hline Investigation & $\mathbf{n}$ & $\begin{array}{l}\text { \% Correct } \\
\text { pre-camp }\end{array}$ & $\begin{array}{c}\text { \% Correct } \\
\text { post-camp }\end{array}$ & X2 & df & $p$-value \\
\hline Aquatics & 91 & 40 & 80.6 & 88.9 & 1 & $<.001$ \\
\hline Wildlife & 91 & 38.5 & 78.8 & 97.6 & 1 & $<.001$ \\
\hline Vegetation & 67 & 38.3 & 73.6 & 57.9 & 1 & $<.001$ \\
\hline Archeology & 67 & 17.9 & 60.2 & 74.5 & 1 & $<.001$ \\
\hline
\end{tabular}

Our results suggest that the CCRNC improved campers' perceptions of most leadership skills, while not improving campers' interest in a 4-year college. CCNRC also improved campers' perceptions of their knowledge for all but one natural resource investigations. The results of the knowledge quiz for wildlife, aquatics, vegetation and archeology, indicated that campers' perceptions of increased knowledge were accurate.

\section{Discussion}

\section{Influence of CCNRC on Perceived Leadership Skills}

One goal of many residential natural resources camps is to provide campers with opportunities to practice skills such as general knowledge, positive self-evaluation, teamwork and collaboration, and effectively speaking to both peers and adults (Ryan \& Campa, 2000; Wilson \& Sibthorp, 2018). At CCNRC instructors provide many avenues to practice these skills including group recreation activities, purposeful leadership activities, active natural resource investigations requiring both collaborative and individual activities, and a capstone activity that practices group decision-making, public speaking, and debate. We determined to measure CCNRC's ability to improve youth leadership skills that would fit broadly into the categories: critical thinking, problem solving, communication, self-confidence, interpersonal skills, and teamwork.

Campers reported an increase in many of the self-assessed leadership skills, such as speaking to adults and peers, being a leader in a group, and trying new activities. This finding supports Wilson and Sibthorp's (2018) research that camps can increase campers' confidence in speaking 
Natural Resource Knowledge and Leadership Skills

to adults and willingness to work in teams. By allowing the campers to practice their skills in a variety of settings during investigations and reinforce these through outdoor recreation at CCNRC, participants were more confident in their leadership abilities.

Based on past studies, we hypothesized that attending our camp would increase participants' interest in the natural resources professions (e.g., Bogner, 1998; Dettmann-Easler \& Pease, 1999; Dresner \& Gill, 1994; Gibson \& Chase, 2002). Following camp, CCNRC participants indicated they were more interested in natural resource careers. Bhattacharyya et al. (2011) found the opposite results when studying the impact of a summer camp in Louisiana on campers' interest in science careers. They suggested that a weeklong course may be too short to influence a camper's career path. However, their camp participants were not yet interested in science, whereas CCNRC was advertised to students in biology and agricultural science classes; thus, our campers were more likely interested in science and biology prior to camp. It is possible that attending CCNRC and gaining first-hand experience with the tools, technology, and practices of natural resources career paths helped them become more aware of the opportunities available to students already interested in science.

Following camp, CCNRC campers indicated they were not more interested in pursuing a 4-year college or more interested in learning new facts. This finding may be a result of the bias of the campers that attended camp. Bogner (1998) found that youth enrolling in a National Park camp had a greater interest in natural resources than the average population. Because CCNRC campers were recruited from school biology and agriculture programs, they were a segment of students that participate in after school programs, and perhaps were already planning to attend a 4-year college. This could also be an effect of response-shift bias, which can occur during prepost experience surveys (Bray, Maxwell, \& Howard, 1984; Drennan \& Hyde, 2008; Rohs, 1999). Without a reference to what a camper originally valued, campers may have been unable to select a response that indicated either a positive change or no effect. More than $33 \%$ of CCNRC campers had a negative change in their interest in a natural resources career, potentially diminishing any positive affect CCNRC had at promoting attendance at a 4-year college.

\section{Influence of CCNRC on Perceived and Actual Knowledge}

Successful programs offered at natural resource camps often focus on gains in leadership and communication skills, and science knowledge. We measured increased knowledge in two ways: campers' perceived change in skill or confidence in that subject and a test of content knowledge. 
This study measured confidence in the participants' knowledge gained by asking the campers to rate how much they knew about each subject (or their "expert" level) before and after the camp. Their self-measured expert level statistically improved after the camp, suggesting that CCNRC was teaching campers something that they hadn't known prior to camp. Thus, this newly acquired information made them feel more confident in the subject. These results are similar to Fields' (2009), who determined campers felt that learning from experts in their subjects provided them with greater knowledge than they could obtain in school. In an empirical study of environmental education program evaluations, Stern, Powell, and Hill (2014) determined that activities that allowed for empowerment and self-learning (e.g. independent investigations, group activities) increased participants' perceptions of their abilities and their skill level. In additional to perceived increased knowledge, the campers had higher scores on their knowledge-based tests. Yair (2000) indicated that investigating real issues through experimentation, such as during our topical investigations, facilitated students' academic achievement.

\section{Limitations of Study Design}

We used pre- and post-camp surveys to evaluate the impact of CCNRC. When conducting surveys evaluating a respondent's perceptions pre- and post-experience, a response shift can occur. A campers' perceived overall ability may have been reduced by the experiences the camper had; for example, perhaps they realized their knowledge was limited in scope or their communication skills were less than others in their group. It also possible that the ranking metric did not resonate with the camper and thus the pre- and post-camp responses were arbitrary. Finally, without a reference to their original scores, campers may evaluate their current perceptions regardless of their pre-experience responses (Drennan \& Hyde, 2008). A response shift diminishes our ability to detect a significant impact of the camp.

We investigated the possible influence of a response shift in our survey for those questions that resulted in a negative change in rating for each camper. This was not used in our assessment of camp but for further discussion of our results, and for future research. For each question, we calculated the percentage of campers that had a negative response (Tables 1 and 2). We then excluded all responses that resulted in a negative change in rating and re-calculated the average change. We compared the standard errors of these two averages to determine if there was a statistical difference between the two. For example, $33 \%$ of respondents had a negative change in rating for their response to "interest in attending a 4-year college." By converting 
Natural Resource Knowledge and Leadership Skills

these negative values to 0 (a conservative estimate of 'no change'), the average change in rating increases from $-0.1 \pm 0.13$ to $0.45 \pm 0.09$, a comparatively high average increase. Similarly, converting these negative values to 0 for astronomy increases the average change in rating from $-0.38 \pm 0.27$ to $0.37 \pm 0.13$. Campers had the highest increased rating in the subject of telemetry. While this subject also had $63.6 \%$ campers with a negative change in rating, its average change between pre- and post-camp survey was small enough $(1.41 \pm 0.29)$ that the negative responses did not obscure the significance of this change. In other words, while there were many negative change scores, individually, the difference between pre- and post-camp responses was small (i.e., 4 to 3 rather than 4 to 2), and did not affect our overall ability to detect a positive change in perceived knowledge. Future studies should include a prepost-camp reflective survey to attempt to minimize response shift.

\section{Conclusions}

Past studies have concluded that natural resource camps increase participants' natural resource knowledge and interest. In addition to these effects, the results of our study indicate that a 5day residential camp can positively influence a camper's self-concept of their leadership skills and perceived knowledge, drivers of future leadership and academic motivation. In addition, we found campers had an increased interest in natural resource careers, a critical need indicated by the National Research Council (2012). The approach of CCNRC, with multiple methods to provide opportunities for campers to practice their leadership and knowledge skills in a novel setting, can meet the needs of multiple learning styles and therefore increases the likelihood of an impact on camper's self-assessment of leadership skills and knowledge. Drawing on past research, CCNRC combines the use of experts in natural resource fields to teach investigations based on real-world issues. This direct contact among professionals and campers provides a mentoring figure to those campers interested in a career. This approach also demonstrates the relevance of a variety of natural resource topics in the modern world.

While this study detected significant change in perceived leadership/knowledge and actual knowledge gained, we realize that additional study is needed. It would be informative to determine if there is a direct correlation between natural resource knowledge gained and increased career interest. Also of interest is the relationship between increased knowledge and postsecondary education and professional career. In addition, further research should include refining a pre- post-camp reflective survey to minimize negative response shift. 
Natural Resource Knowledge and Leadership Skills

In closing, to meet the needs of the next generation of scientists, natural resource camps must help to increase academic interest in natural resource as well as increase leadership, selfconfidence, and interpersonal communication. Camps such as CCNRC that implement many learning and interactive strategies could be most effective in engaging youth to develop the skills and academic motivation to pursue natural resource careers and/or connect with the natural world around them.

\section{Acknowledgements}

The authors would like to thank the dozens of volunteers that spend a week each spring assisting with the administration of the Color Country Natural Resource Camp. Additionally, funding for the camp is generously provided by the U.S. Bureau of Land Management. In-kind support for the camp is provided by the U.S. Forest Service, the Utah Division of Wildlife Resources, Utah State University Extension, and many others.

\section{References}

Anderson-Howe, H. (1993). Participation and motives in sport relative to perceived competence. (Unpublished master's thesis). McGill University, Montreal, Quebec.

Andrejewski, R. (2011). Nature connection, outdoor play, and environmental stewardship in residential environmental education (Doctoral dissertation). Pennsylvania State University, University Park, Pennsylvania. Retrieved from https://etda.libraries.psu.edu/catalog/11673.

Bexell, S. M., Jarrett, O. S., \& Ping, X. (2013). The effects of a summer camp program in China on children's knowledge, attitudes, and behaviors toward animals: a model for conservation education. Visitor Studies, 16(1), 59-81.

Bhattacharyya, S., Nathaniel, R., \& Mead, T. P. (2011). The influence of science summer camp on African-American high school students' career choices. School Science and Mathematics, 111(7), 345-353. doi:10.1111/j.1949-8594.2011.00097.x

Bogner, F. X. (1998). The influence of a short-term outdoor ecology education on long-term variables of environmental education. Journal of Environmental Education, 29(4), 17-29. doi:10.1080/00958969809599124

Bray, J. H., Maxwell, S. E., \& Howard, G. S. (1984). Methods of analysis with response-shift bias. Educational and Psychological Measurement, 44(4), 781- 804. doi:10.1177/0013164484444002

Bureau of Labor Statistics. (2017). Occupational outlook handbook. Retrieved from https://www.bls.gov/ooh/ 
Natural Resource Knowledge and Leadership Skills

Dahlgaard, P. (2008). Introductory statistics with R. New York, NY: Springer,

DeCastellarnau, A. (2018). A classification of response scale characteristics that affect data quality: a literature review. Quality \& Quantity, 52(4), 1523-1559. doi:10.1007/s11135-017-0533-4

Dettmann-Easler, D., \& Pease, J. L. (1999). Evaluating the effectiveness of residential environmental education programs in fostering positive attitudes toward wildlife. Journal of Environmental Education, 31(1), 33-39. doi:10.1080/00958969909598630

Drennan, J., \& Hyde, A. (2008). Controlling response shift bias: the use of the retrospective pre-test design in the evaluation of a master's programme. Assessment \& Evaluation in Higher Education, 33(6), 699-709. doi:10.1080/02602930701773026

Dresner, M. \& Gill, M. (1994). Environmental education at summer nature camp. Journal of Environmental Education, 25(3), 35-41. doi:10.1080/00958964.1994.9941956

Faye, C. \& Sharpe, D. (2008). Academic motivation in university: The role of basic psychological needs and identify formation. Canadian Journal of Behavioural Science, 40(4), 189-199. doi:10.1037/a0012858

Fields, D. A. (2009). What do Students Gain from a Week at Science Camp? Youth perceptions and the design of an immersive, research-oriented astronomy camp. International Journal of Science Education, 31(2), 151-171. doi:10.1080/09500690701648291

Gibson, H. L. \& Chase, C. (2002). Longitudinal impact of an inquiry-based science program on middle school students' attitudes toward science. Science Education, 86(5), 693-705. doi:10.1002/sce.10039

Griffin, K. R., Glasscock, S. N., Schwertner, T. W., Atchley, W. \& Tarpley, R. S. (2016). Wildlife conservation camp: An education and recruitment pathway for high school students? Wildlife Society Bulletin, 40(4), 643-653. doi:10.1002/wsb.710

Hindes, Y. (2011). Examining youth leadership through the development and validation of a self-report measure: the youth leadership questionnaire (YLQ) (Unpublished doctoral dissertation). University of Calgary, Calgary, Alberta.

Love, B. (2003). Relationship between perceptions of classroom climate and students' perceptions of competence and motivational orientation (Unpublished doctoral dissertation). Northern Illinois University, Dekalb, Illinois.

National Research Council (NRC). (2012). Education for Life and Work: Developing Transferable Knowledge and Skills in the $21^{\text {st }}$ Century. Washington, DC: The National Academies Press. doi:10.17226/13398

National Science Board. (2014). Science and engineering indicators. Retrieved from https://www.nsf.gov/statistics/seind14/content/overview/overview.pdf

Nichols, J. D., \& Utesch, W. E. (1998). An alternative learning program: Effects on student motivation and self-esteem. Journal of Educational Research, 91(5), 272-278. doi:10.1080/00220679809597554 
Journal of Youth Development | http://jyd.pitt.edu/ | Vol. 14 Issue 4 DOI 10.5195/jyd.2019.792 Natural Resource Knowledge and Leadership Skills

Knapp, D. \& Poff, R. (2001). A qualitative analysis of the immediate and short-term impact of an environmental interpretive program. Environmental Education Research, 71 ), 55-65. doi:10.1080/13504620124393

Rohs, F. R. (1999). Response shift bias: A problem in evaluating leadership development with self-report pretest-posttest measures. Journal of Agricultura/ Education, 40(4), 28-37. doi:10.5032/jae.1999.04028

Riedinger, K. (2015). Identity development of youth during participation at an informal science education camp. International Journal of Environmental and Science Education, 10(3), 453-475. doi:10.12973/ijese.2015.254a

Ryan, M. R., \& Campa, H., III. (2000). Application of learner-based teaching innovations to enhance education in wildlife conservation. Wildlife Society Bulletin, 28(1), 168-179.

San Jose, A., \& Nelson, K. (2017). Increasing children's positive connection to, orientation toward, and knowledge of nature through nature camp experiences. International Journal of Environmental and Science Education, 12(5), 933-944.

Stern, M. J., Powell, R. B., \& Hill, D. (2014). Environmental education program evaluation in the new millennium: What do we measure and what have we learned? Environmental Education Research, 20(5), 581-611. doi:10.1080/13504622.2013.838749

Thurber, C. A., Scanlin, M. M., Scheuler, L. \& Henderson, K. A. (2007). Youth development outcomes of the camp experience: evidence for multidimensional growth. Journal of Youth and Adolescence, 36(3), 241-254. doi:10.1007/s10964-006-9142-6

Wilson, C., \& Sibthorp, J. (2018). Examining the role of summer camps in developing academic and work readiness. Journal of Youth Development, 13(1-2), 83-102. doi:10.5195/jyd.2018.563

Yair, G. (2000). Reforming motivation: how the structure of instruction affects students' learning experiences. British Educational Research Journal, 26(2), 191-210.

doi:10.1080/01411920050000944 


\section{Appendix}

The pre- and post-camp survey administered to participants of the Color Country Natural Resource Camp, 2013-2018. Verbiage modification occurs each year to reflect changes in activities.

\section{Color Country Natural Resource Camp \\ Panguitch, Utah \\ Dates: May 29 - June 2, 2018 \\ POSTTEST}

\section{Personal ID:}

\section{Age:}

First Time at Camp? Yes or No

How did you hear about us?

Section 1: This section of the survey is designed to gain some insight into YOU. Please remember that you will be assigned a numerical ID and that your responses are therefore anonymous. Please feel comfortable answering honestly to the best of your ability. This portion of the survey really helps us know if we are having a successful camp!

\begin{tabular}{|l|c|c|c|c|c|c|}
\hline Personal statement: & $\begin{array}{c}0 \\
\text { Absolutely } \\
\text { not }\end{array}$ & $\begin{array}{c}1 \\
\text { Not } \\
\text { usually }\end{array}$ & $\begin{array}{c}2 \\
\text { Sometimes, } \\
\text { it depends }\end{array}$ & $\begin{array}{c}3 \text { About } \\
50 \% \text { of } \\
\text { the time }\end{array}$ & $\begin{array}{c}4 \\
\text { Usually }\end{array}$ & $\begin{array}{c}5 \text { Yes, } \\
\text { all the } \\
\text { time }\end{array}$ \\
\hline $\begin{array}{l}\text { I feel comfortable } \\
\text { speaking around people } \\
\text { my age. }\end{array}$ & & & & & & \\
\hline $\begin{array}{l}\text { I feel comfortable } \\
\text { speaking in front of } \\
\text { adults. }\end{array}$ & & & & & & \\
\hline $\begin{array}{l}\text { I enjoy trying new } \\
\text { activities. }\end{array}$ & & & & & & \\
\hline $\begin{array}{l}\text { I enjoy learning new } \\
\text { facts. }\end{array}$ & & & & & & \\
\hline $\begin{array}{l}\text { I am confident solving } \\
\text { problems on my own, } \\
\text { not as a group. }\end{array}$ & & & & & & \\
\hline
\end{tabular}


Natural Resource Knowledge and Leadership Skills

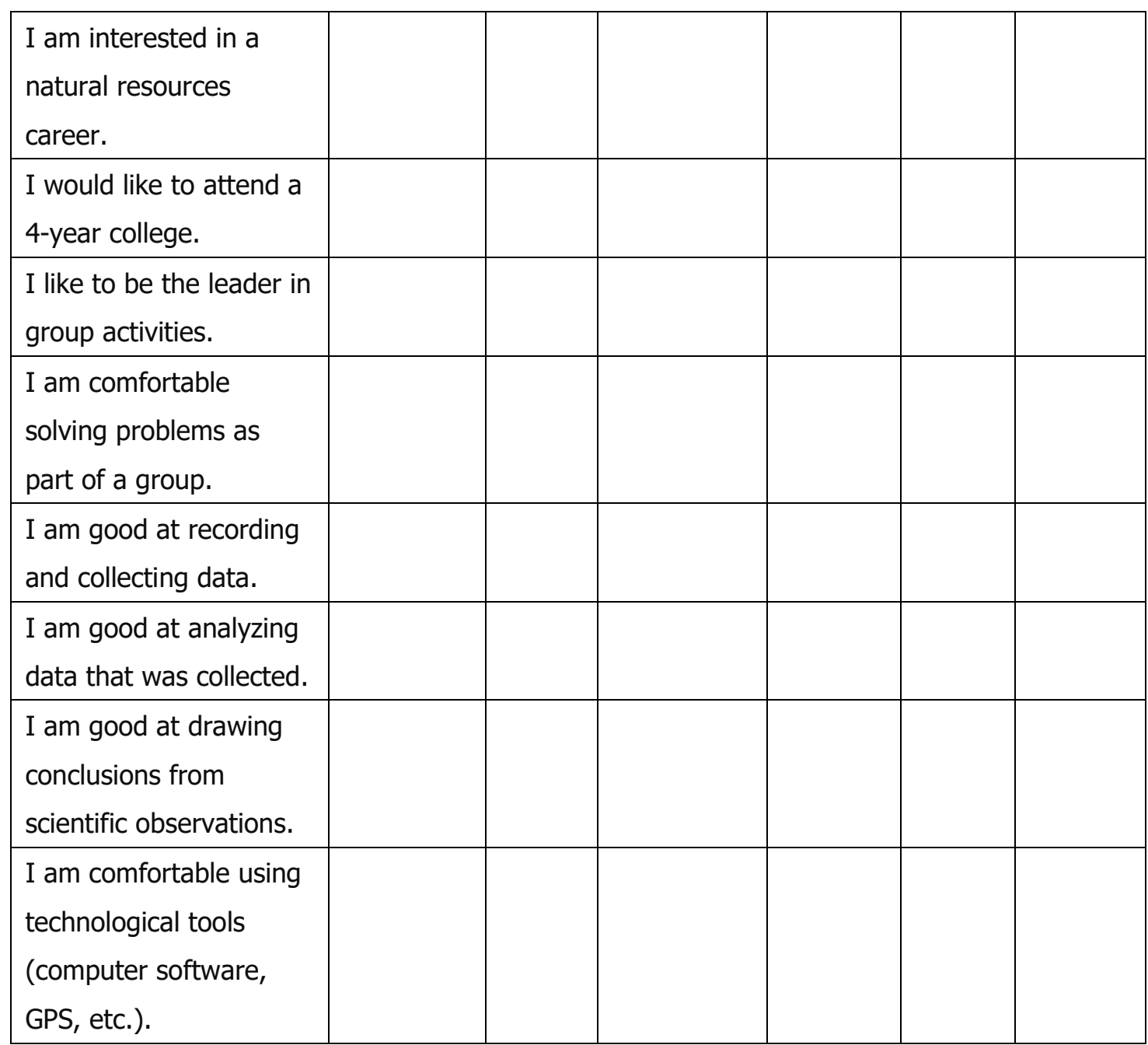

Section 2: This section of the survey is designed to measure your increased understanding of several educational and recreational topics experienced at camp. For each topic of study, please circle the number that best describes your ability, using this key:

1 = completely new to me

2 = I heard about it, but don't know anything about it

3 = I've had some classes in it, or experience in it

4 = I am comfortable talking about this subject to adults, I can answer most questions correctly 5 = I could probably assist in teaching this subject; I consider myself a leader in this topic 
Natural Resource Knowledge and Leadership Skills

\begin{tabular}{|l|c|c|c|c|c|}
\hline How would you describe your & \multicolumn{5}{|c|}{ My Understanding } \\
\cline { 2 - 6 } understanding of the following subjects? & None & $\begin{array}{r}\text { Heard } \\
\text { About }\end{array}$ & Some & $\begin{array}{c}\text { Quite a } \\
\text { Bit }\end{array}$ & Leader \\
\hline $\begin{array}{l}\text { Wildlife identification, ecology and/or } \\
\text { management }\end{array}$ & 1 & 2 & 3 & 4 & 5 \\
\hline $\begin{array}{l}\text { Vegetation identification, ecology, and/or } \\
\text { management }\end{array}$ & 1 & 2 & 3 & 4 & 5 \\
\hline $\begin{array}{l}\text { Aquatic ecology, fish identification, } \\
\text { aquatic invertebrate identification and/or } \\
\text { water quality }\end{array}$ & 1 & 2 & 3 & 4 & 5 \\
\hline Outdoor recreation management & 1 & 2 & 3 & 4 & 5 \\
\hline Outdoor survival & 1 & 2 & 3 & 4 & 5 \\
\hline Compass use, map reading & 1 & 2 & 3 & 4 & 5 \\
\hline Archeology & 1 & 2 & 3 & 4 & 5 \\
\hline Bird rehabilitation & 1 & 2 & 3 & 4 & 5 \\
\hline Soil structure and use & 1 & 2 & 3 & 4 & 5 \\
\hline
\end{tabular}

For each recreational activity, please circle the number that best describes your ability, using this key:

$1=$ completely new to me

2 = I heard about it, but don't know anything about it

3 = I've had some training in it, or experience in it

4 = I am comfortable in this activity, and can initiate this activity by myself

5 = I could probably assist in teaching this subject; I consider myself a leader in this activity

\begin{tabular}{|l|c|c|c|c|c|}
\hline \multirow{2}{*}{$\begin{array}{l}\text { How would you describe your experience with } \\
\text { the following recreation }\end{array}$} & \multicolumn{5}{|c|}{ My Experience } \\
\cline { 2 - 6 } & None & $\begin{array}{c}\text { Heard } \\
\text { About }\end{array}$ & Some & $\begin{array}{c}\text { Quite a } \\
\text { Bit }\end{array}$ & Leader \\
\hline Astronomy & 1 & 2 & 3 & 4 & 5 \\
\hline Hip-hop dancing & 1 & 2 & 3 & 4 & 5 \\
\hline Canoeing & 1 & 2 & 3 & 4 & 5 \\
\hline Archery & 1 & 2 & 3 & 4 & 5 \\
\hline Mountain biking & 1 & 2 & 3 & 4 & 5 \\
\hline Shooting sports & 1 & 2 & 3 & 4 & 5 \\
\hline
\end{tabular}


Section 3: This section of the survey is designed to measure your increase in knowledge from your participation in camp. Please answer the following questions to the best of your ability. If you don't know the answer, try your best guess rather than leaving a blank.

1. What is a watershed?

2. Define an aquatic invertebrate and explain why they are considered an indicator organism?

3. List some water quality measurements you could collect in a stream to determine how healthy it is.

4. What do we look at on an animal to guess what species it might be?

5. What is a line-transect survey?

6. What environmental factors influence the species of vegetation found in an ecosystem?

7. What is transpiration?

8. How can we prevent erosion while recreating?

9. What are 3 types of soil?

10. What is an atlatl?

11. What prehistoric people/society used to live in the Panguitch area?

12. Who were the Archaeo people? 